\title{
CHAPTER SEVEN SOCIAL LEARNING AND CULTURAL TRADITION
}

\author{
Interpreting Early Palaeolithic technology \\ STEVEN MITHEN
}

\section{INTRODUCTION}

The problem archaeologists face when interpreting the stone tools of modern humans is that tools are made under the joint influences of tradition and current needs. As these are not easily separated, the interpretation of stone tools requires extensive reference to both cultural tradition and patterns of economic, social and symbolic behaviour-a daunting task for the archaeologist. My argument in this chapter is that for the Early Palaeolithic the task is perhaps less complex, for tradition heavily outweighed a consideration of current needs in the minds of early tool-makers. This derives, I will argue, from the domain-specific mentality of early humans which prevented the complex integration of thought about technology, social interaction and environmental adaptation that is pervasive among modern humans (Mithen 1994a). In this regard, to further our understanding of early technology, archaeologists need to develop their understanding of 'tradition'-how it arises, how it is transmitted and how it is transformed. Key foci must be the processes of social learning, how these vary between individuals and groups and how this variability influences Early Palaeolithic technology. As a contribution to this task, I will suggest a model for the relationship between social learning, group size and hominid technology and attempt to evaluate it by two case studies from the Early Palaeolithic. Prior to this, I must briefly consider the interaction between tradition and the process of adaptation in modern humans and why this appears to have been absent among early humans.

\section{TRADITION, ADAPTATION AND MODERN TECHNOLOGY}

A modern knapper partly acquires his/her skill by social learning and is therefore influenced by the 'traditional' way of making tools. But he/she is also producing tools for specific functional tasks which may be different to those faced by previous generationsperhaps the type of game is different and the 'traditional' form of a projectile point is no longer effective. As such the cultural tradition may evolve in a direction which results in tools becoming more appropriate for the current ecological context. At any one time the form of a stone tool, and the manner in which it is made, is likely to result from a complex interplay between the influences of tradition and the process of adaptation. 
The difficulty this creates for the interpretation of stone tools is exacerbated because the technology of hunter-gatherers is deeply embedded in multiple domains of behaviour. For instance, Wiessner (1983) described how the arrows of the !Kung play significant roles in the economic domain, as they are used to supply meat; in the social domain, for the provider of meat is responsible for its distribution; and in the domain of myth and folklore, for arrows were used for hunting the eland - an animal of symbolic significance for the !Kung. Consequently when a tool is made, the traditional form of an artefact may be modified not only in light of the changing functional requirements, but also due to the changing social and symbolic contexts in which tools are used.

The embedding of technology in multiple behavioural domains creates substantial problems for interpretation, as can be seen from the Upper Palaeolithic. There are numerous well-preserved late glacial settlements which have been excavated in sufficient detail to allow the re-fitting of a substantial number of flakes, blades and cores, such as at Etiolles (Pigeot 1987) and Hengistbury Head (Barton 1992). These re-fitted cores allow us to monitor the actions of individual flint knappers and to reconstruct the specific choices they made when reducing a nodule of flint. Those choices would have been influenced not only by the acquired cultural tradition but by the intended use of the artefacts in economic, social and symbolic spheres. As we have limited information about late glacial behaviour in each of these, the interpretation of why specific technical decisions were made is difficult. It appears impossible to separate out the features of a stone tool that may be attributed to the following of tradition, the imposition of style and functional utility (Sackett 1982). The task of interpretation is further complicated when we take into account the influence of raw material availability and fracture dynamics on the technological options available to a tool-maker.

According to this argument, as we move from the Later to the Earlier Palaeolithic the interpretation of stone tools ought to become more difficult. As the Earlier Palaeolithic record has a poorer chronological resolution and inferences about social and economic behaviour are generally more difficult, it becomes even more unlikely that we can reconstruct the many factors influencing the decision-making of early tool-makers - if these were similar to those of modern humans. This would remain the case even when the particular decisions are seen with as much clarity as in the Upper Palaeolithic (e.g. from the re-fitted cores of Maastricht-Belvedere, Roebroeks 1988). The argument developed in this chapter is that such pessimistic views are unwarranted.

My argument will be that early technology is fundamentally different in character to that of modern humans and was not embedded in multiple behavioural domains. Indeed, I will suggest that rather than emerging from the joint influences of tradition and adaptation, early technology was heavily dominated by the first of these alone; concerns about creating a functionally efficient tool for a specific task or investing it with social information and symbolic meanings played a minimal role in the decisions of early toolmakers. Consequently, when interpreting the imposed form of early stone tools archaeologists need to make relatively extensive reference to tradition but relatively little reference to function and adaptation.

The ecological context certainly influenced technology. Factors such as raw material availability, transport costs, mobility patterns and the duration of occupation at sites influenced the nature and extent of core and tool reduction (e.g. Rolland and Dibble 
1990, Kuhn 1991). But these factors simply defined the constraints under which early tool-makers worked. As I have discussed elsewhere (Mithen, in press) their technology provides a passive reflection of the ecological constraints as opposed to constituting an active means to restructure the ecological context, as is characteristic of modern technology.

The principal reason for this is likely to be cognitive: the early human mind appears to have had a much higher degree of domain-specific thought resulting in a technological behaviour being relatively isolated from other behavioural domains (Mithen 1994a, in press). Consequently when decisions about making tools were made, these were not influenced by thought about specific foraging tasks or the need to imbue an artefact with social and symbolic information. Without these influences, tradition, together with ecological constraints, must be seen as the principal influence over artefact form.

\section{DOMAIN-SPECIFIC INTELLIGENCE AND EARLY TECHNOLOGY}

It has long been argued that Early Palaeolithic technology is fundamentally different in character to that of modern humans. The limited technological variability across time and space during the Lower and Middle Pleistocene suggests that it is not being used to adapt to environments in the same way as modern technology and does not carry social and symbolic information. Binford (1989) characterized it as an 'aid to', rather than the 'means of' adaptation. Isaac (1972) argued that much of Middle Pleistocene technological variability may be no more than a 'random walk pattern', while Foley (1987) argued that early tools should be analysed as if they were biological, rather than cultural, traits of early hominids. Several archaeologists have suggested that early technology has more in common with that of modern apes, rather than modern humans (e.g. Wynn and McGrew 1988, Davidson and Noble 1993).

The problem with these interpretations is that they do not account for the high levels of technological skill and investment involved in many early industries. The manufacture of a fine, symmetrical Acheulian handaxe, or a Levallois core, is unlikely to have been any less complex than Upper Palaeolithic blade tools. Indeed the production of Oldowan tools required an understanding of fracture mechanics far in advance of that displayed by modern apes (Toth and Schick 1993, Toth et al. 1993). Moreover, it is also clear that in some contexts early humans were imposing specific forms onto their tools, likely to reflect mental templates of desired artefacts (Gowlett 1984).

The paradox faced by Palaeolithic archaeologists is that when the spatial and temporal variability of early technology is examined, it looks very different to that of modern humans, but when the technological skill and imposition of form (found in some but not all industries) is considered, the technology appears to be very similar to that of modern humans. A resolution of this paradox may be found in the nature of the early human mind.

There has been considerable discussion during the last decade as to the extent to which the minds of modern humans and non-human primates are modular, possessing a 'domain specific intelligence'. The notion of mental modularity was largely introduced by Fodor (1983) who argued that the processes of perception (in which he included language) were 
encapsulated from each other, 'hard wired', and dependent upon independent neural circuits. Gardner (1983) applied similar ideas to the notion of intelligence by suggesting that the human mind is constituted by multiple intelligences, such as that relating to language use, musical ability and spatial thought. A more extreme approach has been adopted by Cosmides and Tooby (1987, cf. Tooby and Cosmides 1989, Barkow et al. 1992) who argue that the mind is composed of very many discrete modules, each dedicated to an adaptive problem faced by humans in their evolutionary environment. Within studies of non-human primates the notion of a distinct 'social intelligence', deriving from the work of Humphrey (1976) and Jolly (1966), has been very powerful for understanding primate cognition and behaviour. Contrasts have been drawn between the relative levels of social and non-social intelligence among vervet monkeys (Cheney and Seyfarth 1990).

Rozin (1976, Rozin and Schull 1988) argued that the course of human evolution has involved a trend from a 'domain-specific' to a generalized intelligence. Similarly, Gibson (1993) argued that 'hierarchization' - a process by which new and complex cognitive processes are constructed from the interaction of those which will become lower in a cognitive hierarchy - is a critical theme for the evolution of the human mind. I have recently argued that the patterning in the archaeological record appears to confirm these ideas - the minds of early humans appear to have a much greater degree of domainspecific thought than those of modern humans (Mithen 1994a, in press). Indeed, I have argued that the Middle/Upper Palaeolithic transition marks a major cognitive development towards a generalized intelligence in which cognitive processes which had evolved with regard to very specific activities, such as mediating social interaction, become accessible to thought about other activities. From this increased cognitive accessibility, new capacities developed, such as visual symbolism (Mithen 1994a). This transition from a domain-specific to a generalized mentality is likely to have been a gradual process, with complex relationships to other cognitive developments (such as language). There are likely to have been substantial changes during the course of the Early Palaeolithic and Homo erectus may have had a substantially different degree of domain-specific intelligence than, say, Neanderthals. But in this chapter my concern is with the gross contrast between the Early and the Upper Palaeolithic and between a domain-specific and a generalized intelligence.

The essence of this argument is that during the Early Palaeolithic hominids appear to have had a capacity for complex thought about behaviour in numerous domains, such as technology, social interaction and the natural world, but a limited capacity to integrate such thought. For instance, the detailed understanding of animal behaviour that such hominids required to survive in harsh northern landscapes was not integrated with understanding about lithic technology to produce tools specialized for exploiting specific types of game in specific locations. Such tools only appear after the start of the Upper Palaeolithic. This can be illustrated by weapon tips. During the Upper Palaeolithic and Mesolithic there was an impressive variety of points (e.g. Peterkin 1993, Pike-Tay and Bricker 1993), which can be interpreted as partly deriving from an active engagement with the natural world, such as to cope with time stress or to exploit the specific attributes of game species (Torrence 1983, Bleed 1986, Straus 1990). In contrast, the weapon tips created by Neanderthals in Europe during the Middle Palaeolithic were 'remarkably 
monotonous' reflecting little functional variation (Kuhn 1993) even though Neanderthals lived in a diverse range of environments. Nevertheless, to manufacture Mousterian and Levallois points appears to have involved an equivalent level of technical intelligence to that for making those points of the Upper Palaeolithic. Neanderthals were not generally 'less intelligent', but were unable to integrate their multiple intelligences in the manner of modern humans (Mithen, in press).

The presence of a domain-specific intelligence during the Lower Palaeolithic can be illustrated by comparing the Clactonian and the Acheulian industries of South East England, an example I will return to below. These industries involve a different range of artefact types and different degrees of knapping skill, although there is likely to be a technological continuum rather than sharp divide between them (Ashton 1992). In spite of previous interpretations that these industries were different components of a single 'tool kit' (e.g. Ohel 1979, Roebroeks 1988) it is now clear that they are chronologically independent and were manufactured in different environments with the Clactonian restricted to the Hoxnian interglacial (Wymer 1988), as illustrated in Figure 7.1. Yet there appears to be limited functional differentiation between these industries. Microwear analysis suggests that the core tools (Acheulian handaxes and Clactonian choppers) were used for a similar diverse range of tasks (Keeley 1980) and were not produced for specific tasks appropriate for the resources and structure of those very different environments. In contrast, the technology of modern humans made in glacial and interglacial environments shows dramatic differences (Gamble 1984).

The contrast between the technology of modern and early humans reflects different degrees of integrated thought. For early humans with a high degree of domain-specific thought, technology played a limited active role in adaptive strategies to either the natural or the social environment. While tools were made for functional purposes, these remained at a very generalized level - tools with sharp edges, or which had a substantial mass. Without the influence of thought about the social and natural worlds playing a significant role when tools were being produced, their character was a passive reflection of the ecological and social contexts in which they were produced. Imposed form largely derived from cultural tradition. Consequently, to interpret early technology we need to understand the processes by which tradition is generated and transformed-in other words, the processes of social learning.

\section{SOCIAL LEARNING AND TOOL-MAKING}

Humans learn by a variety of processes which can be placed into two classes: individual and social. The division is one of emphasis rather than kind-all human learning takes place in a social context or uses mechanisms that developed during the course of social interaction. Individual learning involves trial and error and the ill-defined processes of 'thought', 'insight' and 'understanding'. Other learning processes are more explicitly social, notably imitation and tuition. It is likely that people are predisposed to use social and individual learning for different tasks (Rogers 1988). With regard to the development of tradition these are 


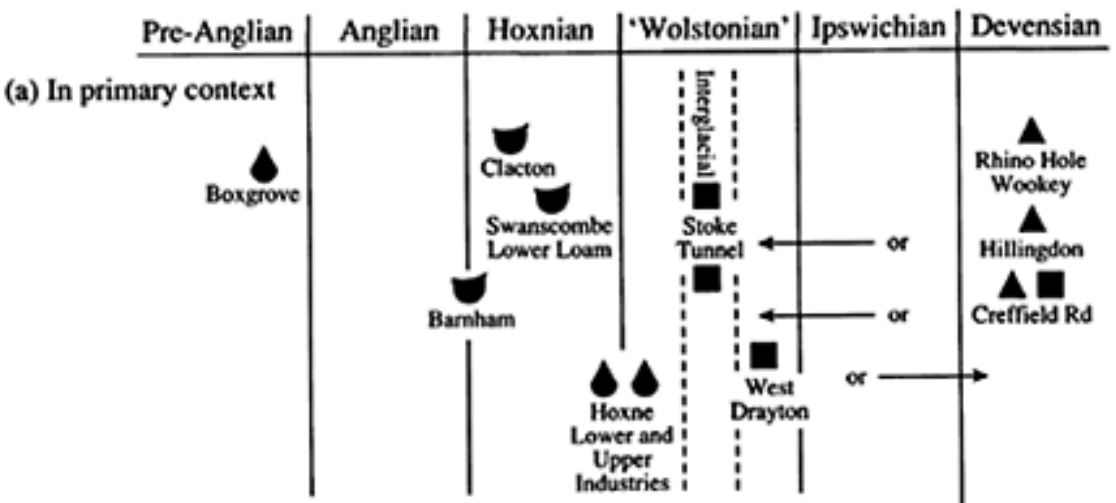

(b) In secondary context but with high probability of being contemporary with the deposition of the sediment containing them

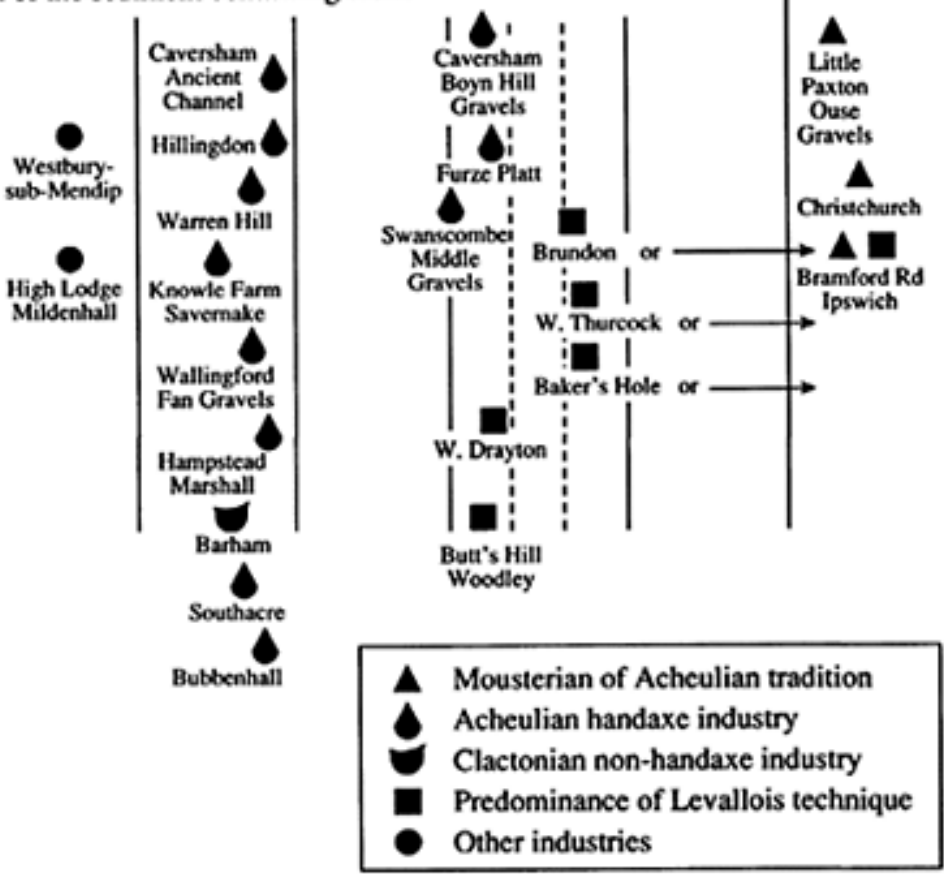

Figure 7.1 Proposed relationship between Lower Palaeolithic assemblages and Pleistocene environmental stages in S.E. England (after Wymer 1988)

pulling in different ways - social learning to propagate traditions, individual learning to dissipate them as people engage in the process of adaptation (Mithen 1989, 1990).

During the last decade there has been considerable interest in the processes of social learning among humans and non-human primates (e.g. Boyd and Richerson 1985, Whiten 1989). This has led to the collapse of many assumptions and the recognition of the 
complexity of social learning. In the following I will highlight some of the major themes in these recent discussions, selecting those which are of particular significance for understanding the acquisition of technological knowledge by early humans.

The principle mechanism of social learning among modern humans is imitation (Meltzoff 1988). The urge to imitate is extremely powerful during early stages of child development (Meltzoff and Moore 1989) and imitation is the basis for the acquisition of cultural behaviour. A decade ago it had been assumed that imitation was also prevalent among non-human primates and led to the spread of cultural behaviours such as foodwashing, placer-mining and stone-handling (e.g. Kawamura 1959, Huffman 1984, Nishida 1987). The extent to which this is the case has recently been questioned (Galef $1988,1990)$ and many primatologists now regard imitation as either absent, or at least very rare, among both monkeys and apes (e.g. Fragaszy and Visalberghi 1990, Visalberghi and Fragaszy 1990, Tomasello 1990, Tomasello et al. 1987, 1993, Whiten 1989). Others disagree and point to apparently clear instances of imitative behaviour among wild chimpanzees (e.g. Boesch 1993) or point to the difficulties in recognizing either the presence or absence of imitation (e.g. Byrne 1993, Hauser 1993). This controversy partly reflects the difficulty of arriving at a workable definition for imitation. Tomasello et al. (1993) suggest three criteria: (a) the acquisition of behaviour that is novel for the imitator; (b) the reproduction of the actual behavioural strategies of the model; (c) behaviour that is directed towards the same goal as the model. But such definitions may be unworkable in practice and can be questioned in principle (e.g. Heyes 1993). One of the difficulties that a domain-specific cognitive perspective creates is that the ability to imitate as a means of social learning may be present in some domains, but absent in others.

The demise of imitation as an explanation for the spread of cultural behaviour among extant non-human primates has promoted an interest in alternative processes of social learning which are likely to play a major role in both human and non-human societies. The definition of these is plagued by terminological distinctions (Galef 1976) but Byrne (in press) has suggested that there are three principal processes which complement imitation. Stimulus enhancement refers to the increase in the probability that an individual will approach or contact something in the environment when a conspecific is observed with it. This is now thought to be a major process by which cultural behaviours are acquired, but it does not imply that the learner is attempting to acquire the specific goals or methods possessed by the model. Response facilitation refers to an increase in the probability that an individual will perform a certain act, once a conspecific is observed performing it. This is crucially different from stimulus enhancement, because the actual actions of the model are repeated, and from imitation because these actions must already be in the animals behavioural repertoire. Emulation is a further process of social learning in which an individual copies the goal, but not the methods of a conspecific. This is known to be prevalent among humans and is likely to play a significant role in explaining the results of chimpanzee tool-use experiments (e.g. Tomasello et al. 1987).

The above forms of social learning are imitative in nature, even if they do not constitute true imitation. A common feature is that there is no active instruction from the model to the learner. Yet, among humans at least, instructed learning also plays a major 
role in the generation of cultural traditions. Tomasello et al. (1993) suggest that instructed learning is a second stage in the ontogeny of cultural learning and can only arise after the child has developed a theory of mind that enables him/her to understand that another person may have a different mental perspective than his/her own. This generally occurs at around the age of 4 years. Instructed learning takes many forms ranging from simply providing the child with the facilities to encourage his/her own learning to providing a set of instructions, usually by the spoken word.

Tomasello et al. (1993) suggest that chimpanzees in the wild do not engage in instructed learning; they also doubt the validity of claimed examples of instructed learning among captive chimpanzees. Boesch (1993) has provided possible evidence for instructed learning among wild chimpanzees by describing two instances in which a mother appears to instruct her juveniles in the most appropriate manner to use tools for opening nuts. Even if this is an instance of active instruction (Tomasello et al. 1993 deny this) it is perhaps most notable for being so rare-only two out of 977 observed instances of social interaction. Tomasello et al. (1993) suggest that the rarity, or possible absence of instructed learning among chimpanzees is because they cannot conceive of others as mental agents, having thoughts and beliefs that may contrast with their own. This runs counter, however, to a growing body of literature that describes how chimpanzees are capable of deception, which requires a developed theory of mind (e.g. Byrne and Whiten 1988, Whiten 1991).

\section{SOCIAL LEARNING AMONG EARLY HOMINIDS}

As described above there is a marked contrast between the social learning capacities of modern humans and non-human primates. This contrast may be qualitative, if imitation is truly absent among non-human primates, or more probably simply quantitative if imitation is present but very rarely expressed. The social learning of non-human primates appears to be dominated by processes of social enhancement and response facilitation. These are also pervasive among modern humans, together with emulation, but are outweighed in significance by imitation.

What were the social learning capacities of pre-modern hominids, Homo erectus and archaic Homo sapiens? As these share a common ancestor with the chimpanzee we must at least attribute them with capacities for social enhancement and response facilitation. It would also appear, however, that imitation played a significant role in the transmission of technical knowledge - in some instances. Perhaps the most remarkable feature of the Acheulian is the similarity in the form and manufacturing processes of handaxes across wide areas (e.g. Wynn and Tierson 1990). Within individual assemblages the similarity between artefacts is often so remarkable that a single knapper may be responsible for several artefacts (e.g. Tyldesley 1986). Yet it is more likely that this simply reflects the presence of strong social learning involving imitation in the transmission of technical knowledge. Indeed, the technical skill required to make some handaxes may suggest that instructed learning was necessary (Dennell 1994), which in turn has implications for the evolution of language.

It is clear, however, that in many assemblages there is a marked absence of typological 
and technological similarity between artefacts. The Clactonian provides a classic example in which, although some technical features are shared, it is difficult to identify 'types' and the reduction methods are highly variable (Wymer 1974, 1985, Newcomer 1979, Ohel 1979, Roe 1979, 1981). Moreover, the level of technical skill is relatively low, compared to that required to manufacture a handaxe. It would appear that imitation and instructed learning are not playing significant roles in the transmission of technical knowledge. The technical traditions of the Clactonian may be accounted for by weak social enhancement and/or response facilitation alone.

In this regard a major dimension of the variability in Early Palaeolithic assemblages may be accounted for by the variability in the expression of social learning capacities and consequently the role of tradition in artefact manufacture. No doubt other variables are also playing a role, such as variability in raw material quality and availability. But if archaeologists are to explain the variability in the archaeological record, they need to understand the conditions under which the various processes of social learning will be expressed. Under what conditions, for instance, will imitation play a significant role in the transmission of technical knowledge? One possibility, which I will now explore, is when hominids are living in relatively large groups.

\section{GROUP SIZE, SOCIAL INTERACTION AND SOCIAL LEARNING}

Non-human primates live in groups which vary markedly in their size, although each species appears to have a modal value for group size (Dunbar 1988, 1991). This variability in group size - whether between or within species - has been interpreted by ecologists as reflecting the adaptive strategies of individual animals. Living in large social groups may provide considerable benefits. It may substantially decrease the chance of predation and/or increase foraging efficiency if resources are patchily distributed in large clumps (Clutton-Brock and Harvey 1977, van Schaik 1983, see Dunbar 1988 for a review of causes of group size). On the other hand there are disadvantages to living in a large group in terms of competition for resources (Wrangham 1987). The frequency of aggressive encounters appears to be directly correlated with group size and the extent to which food is clumped (Dunbar 1988:113-115). Living in large groups requires extensive social knowledge about other group members and requires the investment in time to service the key relationships which maintain group stability (Dunbar 1991, Aiello and Dunbar 1993).

As a consequence there are often intense relationships between individuals within large groups. The high level of stress may lead to intense bonding within kin groups and the formation of coalitions between kin and non-kin. Specific forms of social interaction, such as grooming, are likely to play an important role in maintaining relationships; Dunbar (1991) has noted that the time spent grooming appears to be positively correlated with group size. The risk of harassment by conspecifics, and/or the risk of predation, may promote paternal care of infants, possibly as a means to maintain relationships with a female (Whitten 1987). Predator risk may promote high levels of social cohesion in general (Kummer et al. 1985) and Dunbar (1988:303) has noted particularly high levels of social interaction in populations which form unusually large groups. 
These causes and consequences of large group size are likely to be as applicable to hominids as to any other large terrestrial primate. But one further consequence, especially significant for hominids with their reliance on stone tools and capacity for strong social learning, is that as group size increases we should expect the opportunities for social learning (of whatever form) to increase. The frequency of innovation is likely to decrease as juveniles will be encouraged to feed with and remain spatially close to adults, especially their kin, due to the high level of social harassment and the clumping of food. Consequently, the relative role of social to individual learning will increase. Similarly, the rate of cultural transmission will increase. Individuals will be able to observe the actions of other individuals, such as their manipulation of objects more frequently and in more detail when living in large groups, due to the importance of intense kin-bonding, coalitions and the high frequency of visual monitoring and social interaction in general. This increased opportunity for observation will increase the extent of stimulus enhancement, response facilitation, true imitation and emulation. It may also increase the probability that individuals will engage in instructed learning.

\section{GROUP SIZE AND INDUSTRIAL VARIABILITY}

The implications of the changing patterns of social learning between small and large groups for hominid technology are substantial (Mithen 1994b). When living in small groups knapping procedures are likely to be diverse due to the absence, or weak influence, of cultural traditions of artefact manufacture. Similarly, artefact form will be diverse and heavily influenced by raw material characteristics. Knapping skill will also be limited since the 'ratchet' effect deriving from cumulative technical experience will be constrained by the low degree of social learning. As with modern primates, each generation may be struggling to reach the level of technical skill achieved by the preceding generation.

In contrast, when hominids are living in larger groups, social learning will become more significant - the rate of innovation will decrease, while the transmission of a new cultural trait will increase. The consequences for technology are that common knapping procedures and artefact forms will be found throughout the group and a relatively high level of technical skill may develop due to cumulative experience. We should still expect artefacts displaying low levels of technical skill and shared features to be produced, as the artefacts deriving from the shared cultural traditions of the group are likely to be additions to, rather than replacements of, the technological repertoire.

The influences of increased social learning on hominid technology will only be realized if raw material characteristics are appropriate. If a material with poor flaking characteristics is being worked (such as a coarse-grained quartzite), so that it is very difficult to remove a flake of a specific size and shape, there will be a constraint upon the expression, and consequently transmission and development of technical skill and shared artefact forms. With such materials, the technology of hominids in large groups, experiencing strong social learning, may be indistinguishable from that of hominids in small groups with weak social learning. 


\section{EVALUATING THE MODEL: HOMINID GROUP SIZE DURING THE EARLY PALAEOLITHIC}

The above model has set up some expectations concerning how hominid technology should vary with hominid group size under the joint conditions of a domain-specific intelligence and raw materials which allow the expression of technological skill and the imposition of form. Evaluating the model requires that we can make estimates for past hominid group size.

This is, perhaps, one of the most difficult tasks for the Palaeolithic archaeologist. In the vast majority of sites the extent of post-depositional disturbance has been so substantial that we have little idea about original site structure. And even when extensive areas of in situ remains are preserved, we lack any methodology to move from that data to past group size. Due to the difference in the cognitive characteristics I have outlined above, it is unlikely that those methods which may allow us to estimate the hunter-gatherer group size from site structure (e.g. O'Connell 1987) of modern humans will be applicable to the early Palaeolithic. The spatial behaviour and resulting site structure of early humans appears to be principally episodic in nature and in marked contrast to that of modern humans (Stringer and Gamble 1993).

A consequence of the absence of a methodology for inferring past group size directly from archaeological data is that we need to turn to indirect evidence. There are two sources: hominid brain size and palaeoenvironments. The first may allow us to make an estimate for the absolute modal group size of a hominid species, while the second allows us to estimate the relative group size for the same species when living in different environments.

\section{GROUP SIZE AND NEOCORTEX RATIO: THE OLDOWAN AND ACHEULIAN}

Dunbar (1992) has shown that among living primates there is a strong positive correlation between group size and the neocortex size. As there is also a correlation between brain size and neocortex size, and the brain size of hominids can be derived from fossil endocasts, estimates for the modal group size of early Palaeolithic hominids can be made. In this regard we can make an indirect estimate for the modal group size of past hominids.

According to the figures provided by Aiello and Dunbar (1993) the modal group size for Homo habilis/rudolfensis is c. 82, that for Homo erectus is c. 111 and that for Archaic Homo sapiens c. 137, the last being not significantly different to that of modern humans. Here we should focus on the contrast between Homo habilis/rudolfensis and Homo erectus and note that as group size is significantly larger for the later species, we should expect an increase in the extent of social learning, and consequently cultural tradition should be a more pervasive influence over technology and artefact form. I am not concerned with the accuracy of the specific figures for group size that Aiello and Dunbar propose. The derivation of their figures involves several assumptions about appropriate 
statistical methods and the importance of their work for this chapter is simply that group size of Homo erectus is predicted to be significantly larger than that for Homo habilis/rudolfensis - the extent of the difference is open to debate.

Although it is possible that Australopithecines were making early artefacts (Susman 1991), the Oldowan is conventionally attributed to Homo habilis/rudolfensis, while the developed Oldowan and the Acheulian were produced by Homo erectus. In spite of the disagreement about the complexity of both Oldowan and Acheulian technologies (e.g. Toth 1985, Wynn and McGrew 1988, Davidson and Noble 1993, Toth and Schick 1993, Toth et al. 1993), there can be little doubt that the latter displays a higher level of technical skill and cultural traditions in artefact form. 'Types' are likely to be absent in the Oldowan (Toth 1985, Potts 1988), while with the early Acheulian, bifaces are being produced with imposed form, probably resulting from mental templates (Gowlett 1984, Wynn 1989).

While the Oldowan/Acheulian contrast follows our expected pattern of technological change with group size, mediated by increased social learning, it may also be accounted for by other factors. We may be witnessing a general increase in the overall capacity for social learning between Homo habilis and Homo erectus, rather than simply an increase in its expression. Homo habilis may well have possessed a repertoire of social learning capacities more similar to modern apes, in which, as discussed above, imitation may be absent. A second problem, is that the Acheulian is a very diverse industry with marked variability in technological skill and the extent of shared artefact form. Moreover, Homo erectus and archaic Homo sapiens, in some areas and at some times, had a pebble/flake industry which was more similar to the Oldowan than the Acheulian (e.g. Vértesszöllös, Bilzingsleben, Isernia, Clacton-Wymer 1974, Vértes 1975, Svoboda 1987). This level of technological variability may be accounted for by variation in group size within species, and provides a more effective evaluation of the proposed model.

\section{GROUP SIZE AND PALAEOENVIRONMENTS: THE ACHEULIAN AND CLACTONIAN}

As noted above, primate group size is likely to be relatively large under conditions of high predator risk and resource clumping. Both of these tend to be associated with open, rather than closed (i.e. wooded) landscapes. Trees provide a means to hide and escape from predators, while in open landscapes primates remain at high risks of detection. In wooded landscapes both animal and plant resources are likely to be more dispersed and to come in smaller packages than in open landscapes. In these, hominids are likely to have been dependent upon meat, possibly scavenged from carcasses (Gamble 1987). Consequently, we should expect hominids to have lived in relatively larger groups in open rather than closed landscapes.

We know that the extent of tree cover has varied markedly during the Pleistocene. At a gross level, we know there to have been at least eight glacial/interglacial cycles during the Middle and Upper Pleistocene and these involved the environment switching from open to closed landscapes (Shackleton and Opdyke 1973, West 1977). Within any one glacial or interglacial phase there was also substantial environmental variability through 
time and space. As the environments changed during the course of the Pleistocene, hominids adapted their behaviour to fit the changing

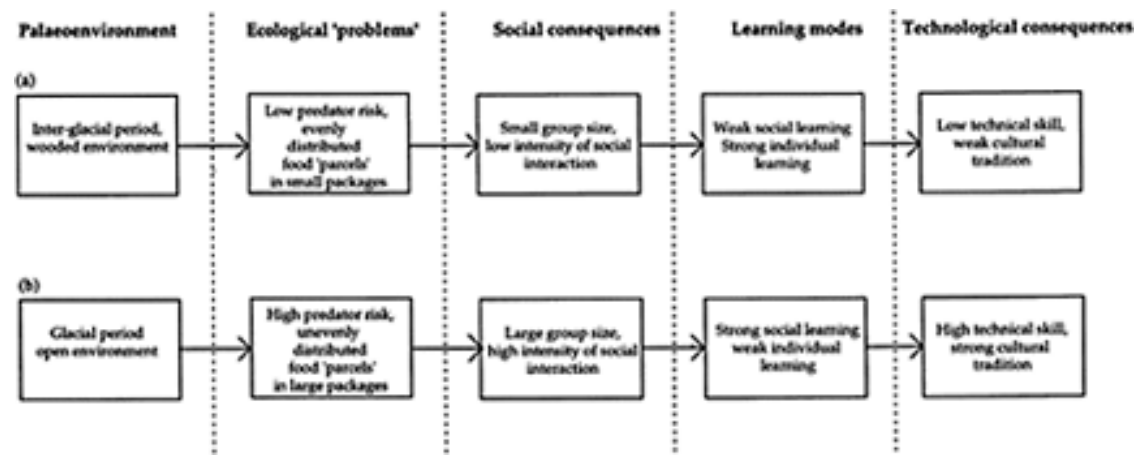

Figure 7.2a Proposed causal relationships between closed (i.e. wooded) environments and early hominid technology, as mediated by social interaction and social learning. This scenario is suggested as applicable to the Lower Palaeolithic Clactonian industry of S.E. England

Figure 7.2b Proposed causal relationships between open environments and early hominid technology, suggested as being applicable to Lower Palaeolithic Acheulian industry in S.E. England

conditions. Unlike modern humans, they appear to have been unable to cope with the extreme conditions of either very thickly wooded or barren tundra landscapes at the peak of an interglacial or glacial (Gamble 1986, 1992, Roebroeks et al. 1992).

One response of the hominid populations to changing environments is likely to have been an adjustment in group size for the reasons of predator defence and/or resource exploitation as described above. Consequently, according to the above model, we should expect to find some correlation between technological variability and palaeoenvironments, with hominid group size and social learning as the mediating factors (Figure 7.2). During periods in which landscapes were relatively treeless, we should expect hominids to have formed relatively large groups and for social learning to have played a substantial role in the acquisition of technical knowledge. As a result, and if raw materials are suitable, we should expect to find artefacts which display high levels of skill, morphological and technological similarity. In contrast, during periods in which the landscape was wooded, hominid group size is likely to have been low, social learning weak and technology to have remained relatively simple. We should expect artefacts to display considerable variability in form and manufacturing process.

This hypothesized relationship between stone tool technology and palaeoenvironments is straightforward, but not easy to test. It requires a detailed understanding of the sequence of technological and environmental change in one region in which raw materials are found which may express the changing levels of social learning. The character of the Middle Pleistocene archaeological record makes such opportunities very 
rare (Villa 1991). One region where this appears possible is South East England during the Middle Pleistocene (Mithen 1994b).

There has been a long history of research on the industrial and environmental sequence of South East England. Both of these have been subject to a major re-evaluation in recent years as the complexity of Pleistocene environmental change has been recognized and clear evidence for pre-Anglian occupation acquired (e.g. Roberts 1986, Ashton et al. 1992). The variability in the lithic assemblages has been summarized by identifying two major industrial types, the Clactonian and the Acheulian, whose technological features have been well described and subject to numerous interpretations.

Wymer's (1988) re-evaluation of the environmental and industrial sequence has suggested that the Clactonian can now be confidently placed in the Hoxnian interglacial. Palaeoenvironments during the Hoxnian were thickly wooded (Turner 1970, Kerney 1971, Stuart 1982) and we should expect hominids to have formed relatively small social groups and social learning to have been weakly present. Acheulian assemblages appear to have been only manufactured in the relatively open environments of the glacial phases, when group size is likely to have been large and social learning strong. These industrial/environmental associations fit with the expectations of the model proposed in this paper. The Clactonian involves limited technological skill, lacks artefacts with imposed and shared form, and exhibits a diverse range of knapping methods (Wymer 1974, 1979, Newcomer 1979, Ohel 1979, Roe 1981). In contrast, the Acheulian assemblages involve artefacts which required considerable technical skill to manufacture and which often display strong similarities in form and technology - in other words they exhibit a strong cultural tradition.

\section{CONCLUSION}

Neither of the two case studies briefly described in this chapter are perfectly suited to testing the model concerning hominid technology and group size proposed in this chapter. In both cases group size can only be estimated by indirect evidence, relying on relationships found among modern primates.

Although Palaeolithic archaeologists deal with a vast time span of human prehistory for which there is an extremely poor chronological resolution, they must devote more effort to developing models for micro-scale processes - the decisions and actions of individuals (Mithen 1994c). It was from these that cultural traditions developed and the process of adaptation was accomplished. Similarly, greater attention must be paid to children and the means by which they acquire technical knowledge, to balance the current dominant concern with the manner in which adults exploit such knowledge to make tools. Recent developmental studies of humans, apes and monkeys (e.g. Parker and Gibson 1990, Tomasello et al. 1993) suggest that there is considerable potential for the construction of archaeological models for the cognitive development of juvenile early humans.

For modern humans cultural tradition (acquired by social learning) and the process of adaptation (achieved by individual learning) are likely to have played equivalent roles in the decision-making of tool-makers. Their technology was embedded in multiple 
domains of behaviour and played active roles in the exploitation of the natural world, social interaction and symbolic communication. In contrast, for early humans there appears to have been a greater degree of independence between behavioural domains and while they possessed a high level of technical intelligence, tools were made for generalized purposes and passively reflected the ecological and social conditions of manufacture. As such, their form could become heavily influenced by tradition in contexts when the degree of social interaction-particularly between adults and juveniles - was intense, resulting in strong social learning.

\section{REFERENCES}

Aiello, L.C. and Dunbar, R.I.M. (1993) 'Neocortex size, group size and the evolution of language.' Current Anthropology 34:184-193.

Ashton, N.M. (1992) 'The High Lodge flint industries.' In N.M.Ashton, J.Cook, S.G.Lewis and J.Rose (eds) High Lodge: Excavations by G.de G. Sieveking 1962-68 and J.Cook 1988, pp. 124-163. London: British Museum Press.

Ashton, N.M., Cook, J., Lewis, S.G. and Rose, J. (eds) (1992) High Lodge: Excavations by G.de G.Sieveking 1962-68 and J.Cook 1988. London: British Museum Press.

Barkow, J., Cosmides, L. and Tooby, J. (eds) (1992) The Adapted Mind: Evolutionary Psychology and the Generation of Culture. Oxford: Oxford University Press.

Barton, N. (1992) Hengistbury Head, Volume 2. The Later Upper Palaeolithic and Mesolithic Sites. Oxford: Oxford Committee for Aerial Photography.

Binford, L. (1989) 'Isolating the transitions to cultural adaptations.' In L.Binford, Debating Archaeology, pp. 423-436. New York: Academic Press.

Bleed, P. (1986) 'The optimal design of hunting weapons: maintainability or reliability?' American Antiquity 51:737-747.

Boesch, C. (1993) 'Aspects of transmission of tool-use in wild chimpanzees.' In K.Gibson and T.Ingold (eds) Tools, Language and Cognition in Human Evolution, pp. 171-183. Cambridge: Cambridge University Press.

Boyd, R. and Richerson, P. (1985) Culture and the Evolutionary Process. Chicago: Chicago University Press.

Byrne, R.W. (1993) 'Hierarchical levels of imitation.' Behavioural and Brain Sciences 16:516-517.

Byrne, R.W. (in press) 'The evolution of intelligence.' In P.J.B.Slater and T.R. Halliday (eds) Behaviour and Evolution. Cambridge: Cambridge University Press.

Byrne, R.W. and Whiten, A. (eds) (1988) Machiavellian Intelligence: Social Expertise and the Evolution of Intelligence in Monkeys, Apes and Humans. Oxford: Oxford University Press.

Cheney, D.L. and Seyfarth, R.M. (1990) How Monkeys see the World. Chicago: Chicago University Press.

Cosmides, L. and Tooby, J. (1987) 'From evolution to behaviour: evolutionary psychology as the missing link.' In J.Dupre (ed.) The Latest on the Best: Essays on Evolution and Optimality, pp. 277-306. Cambridge, MA: MIT Press.

Clutton-Brock, T.H. and Harvey, P.H. (1977) 'Primate ecology and social organisation.' Journal of the Zoological Society of London 183:1-39.

Davidson, I. and Noble, W. (1993) 'Tools and language in human evolution.' In K.Gibson and T.Ingold (eds) Tools, Language and Cognition in Human Evolution, pp. 
363-389. Cambridge: Cambridge University Press.

Dennell, R. (1994) 'Comment on Mithen, S.J. "Technology and society during the

Middle Pleistocene".' Cambridge Archaeological Journal 4:24-25.

Dunbar, R.I.M. (1988) Primate Social Systems. London: Croom Helm.

Dunbar, R.I.M. (1991) 'Functional significance of social grooming in primates.' Folia Primatologica 57:121-131.

Dunbar, R.I.M. (1992) 'Neocortex size as a constraint on group size in primates.' Journal of Human Evolution 22:469-493.

Fodor, J. (1983) The Modularity of Mind. Cambridge, MA: MIT Press.

Foley, R. (1987) 'Hominid species and stone tool assemblages: how are they related?' Antiquity 61:380-392.

Fragaszy, D. and Visalberghi, E. (1990) 'Social processes affecting the appearance of innovative behaviours in Capuchin monkeys.' Folia Primatologica 54: 155-165.

Galef, B.G. (1976) 'Social transmission of acquired behaviour: a discussion of tradition and social learning in vertebrates.' In J.S.Rosenblatt, R.A.Hinde, E.Shaw and C.G.Beer (eds) Advances in the Study of Behaviour, Vol. 6, pp. 77-100. New York: Academic Press.

Galef, B.G. (1988) 'Imitation in animals: history, definition and interpretation of data from the psychological laboratory.' In T.R.Zentall and B.G.Galef (eds) Social Learning: A Comparative Approach, pp. 3-28. Hillsdale, NJ: Erlbaum.

Galef, B.G. (1990) 'Tradition in animals: field observations and laboratory analysis.' In M.Bekoff and D.Jamieson (eds) Methods, Inferences, Interpretations and Explanations in the Study of Behaviour, pp. 74-95. Boulder, CO: Westview Press.

Gamble, C. (1984) 'Regional variation in hunter-gatherer strategy in the Upper Pleistocene of Europe.' In R.Foley (ed.) Human Evolution and Community Ecology, pp. 237-260. London: Academic Press.

Gamble, C. (1986) The Palaeolithic Settlement of Europe. Cambridge: Cambridge University Press.

Gamble, C. (1987) 'Man the shoveler: alternative models for Middle Pleistocene colonization and occupation in northern latitudes.' In O.Soffer (ed.) The Pleistocene Old World, pp. 81-98. New York: Plenum Press.

Gamble, C. (1992) 'Comment on "Dense forests, cold steppes, and the Palaeolithic settlement of Northern Europe" by W.Roebroeks, NJ. Conrad and T.van Kolfschoten.' Current Anthropology 33:569-571.

Gardner, H. (1983) Frames of Mind: The Theory of Multiple Intelligences. New York: Basic Books.

Gibson, K. (1993) 'Tool use, language and social behaviour in relationship to information processing capacities.' In K.Gibson and T.Ingold (eds) Tools, Language and Cognition in Human Evolution, pp. 251-270. Cambridge: Cambridge University Press.

Gowlett, J. (1984) 'The mental abilities of early man: a look at some hard evidence.' In R.Foley (ed.) Human Evolution and Community Ecology, pp. 167-192. London: Academic Press.

Hauser, M.D. (1993) 'Cultural learning: are there functional consequences?' Behavioural and Brain Sciences 16:524.

Heyes, C. (1993) 'Imitation without perspective-taking.' Behavioural and Brain Sciences 16:524-525.

Huffman, M. (1984) 'Stone play of Macaca fuscata in Arashiyana B troop: transmission of a non-adaptive behaviour.' Journal of Human Evolution 13: 725-735.

Humphrey, N. (1976) 'The social function of intellect.' In P.P.G.Bateson and R.A.Hinde 
(eds) Growing Points in Ethology, pp. 303-317. Cambridge: Cambridge University Press.

Isaac, G.L. (1972) 'Chronology and the tempo of cultural change during the Pleistocene.' In W.W.Bishop and J.Miller (eds) Calibration of Hominid Evolution, pp. 381-430. Edinburgh: Scottish Academic Press.

Jolly, A. (1966) 'Lemur social behaviour and primate intelligence.' Science 153: 501506.

Kawamura, S. (1959) 'The process of sub-culture propagation among Japanese macaques.' Primates 24:43-60.

Keeley, L. (1980) Experimental Determination of Stone Tool Uses: A Microwear Analysis. Chicago: Chicago University Press.

Kerney, M.P. (1971) 'Interglacial deposits in Barnfield pit, Swanscombe, and their molluscan fauna.' Journal of the Geological Society of London 127:69-93.

Kuhn, S.L. (1991) "“Unpacking” reduction: lithic raw material economy in the Mousterian of west central Italy.' Journal of Anthropological Archaeology 10: 76-106.

Kuhn, S.L. (1993) 'Mousterian technology as adaptive response: a case study.' In G.L.Peterkin, H.M.Bricker and P.Mellars (eds) Hunting and Animal Exploitation in the Later Palaeolithic and Mesolithic of Eurasia. Archaeological Papers of the American Anthropological Association 4:2-31.

Kummer, H., Banaja, A., Abo-khatwa, A. and Ghandour, A. (1985) 'Differences in social behaviour between Ethiopian and Arabian Hamadryas baboons.' Folia Primatologica 45:1-8.

Meltzoff, A.N. (1988) 'Homo imitans.' In T.R.Zentall and B.G.Galef (eds) Social Learning: A Comparative Approach, pp. 319-342. Hillsdale, NJ: Erlbaum.

Meltzoff, A.N. and Moore, M.K. (1989) 'Imitation in newborn infants: exploring the range of gestures imitated and the underlying mechanisms.' Developmental Psychology 25:954-962.

Mithen, S.J. (1989) 'Evolutionary theory and post-processual archaeology.' Antiquity 63:483-494.

Mithen, S.J. (1990) Thoughtful Foragers; A Study of Prehistoric Decision-making. Cambridge: Cambridge University Press.

Mithen, S.J. (1994a) 'From domain-specific to generalised intelligence: a cognitive interpretation of the Middle/Upper Palaeolithic transition.' In C.Renfrew and E.Zubrow (eds) The Ancient Mind, pp. 29-39. Cambridge: Cambridge University Press.

Mithen, S.J. (1994b) 'Technology and society during the Middle Pleistocene.' Cambridge Archaeological Journal 4:3-33.

Mithen, S.J. (1994c) 'Individuals, groups and the Palaeolithic record: a reply to Clark.' Proceedings of the Prehistoric Society 59:393-398.

Mithen, S.J. (in press) 'Domain-specific intelligence and the Neanderthal mind.' In P.Mellars and K.Gibson (eds) Modelling the Early Human Mind, MacDonald Institute for Archaeological Research Monograph 1. Cambridge: Cambridge University Press.

Newcomer, M. (1979) 'Comment on "The Clactonian: an independent entity or an integral part of the Acheulian”, by M.Y.Ohel.' Current Anthropology 20: 717.

Nishida, T. (1987) 'Local traditions and cultural transmission.' In B.B.Smuts, D.L.Cheney, R.M.Seyfarth, R.W.Wrangham and T.T.Struhsaker (eds) Primate Societies, pp. 462-474. Chicago: University of Chicago Press.

O'Connell, J. (1987) 'Alyawara site structure and its archaeological implications.' American Antiquity 52:74-108. 
Ohel, M.Y. (1979) 'The Clactonian: an independent entity or an integral part of the Acheulian.' Current Anthropology 20:685-726.

Parker, S.T. and Gibson, K. (eds) (1990) 'Language' and Intelligence in Monkeys and Apes. Cambridge: Cambridge University Press.

Peterkin, G.L. (1993) 'Lithic and organic hunting technology in the French Upper Palaeolithic.' In G.L.Peterkin, H.M.Bricker and P.Mellars (eds) Hunting and Animal Exploitation in the Later Palaeolithic and Mesolithic of Eurasia. Archaeological Papers of the American Anthropological Association 4:49-68.

Pigeot, N. (1987) Magdaléniens d'Étiolles: Economie de Debitage et Organisation Sociale (Suppl. 25 Gallia Préhistoire). Paris: CNRS.

Pike-Tay, A. and Bricker, H. (1993) 'Hunting in the Gravettian; an examination of evidence from southwestern France.' In G.L.Peterkin, H.M.Bricker and P.Mellars (eds) Hunting and Animal Exploitation in the Later Palaeolithic and Mesolithic of Eurasia. Archaeological Papers of the American Anthropological Association 4:127-144.

Potts, R. (1988) Early Hominid Activities at Olduvai. New York: Aldine de Gruyter.

Roberts, M. (1986) 'Excavations of the Lower Palaeolithic site at Amey's Eartham pit, Boxgrove, West Sussex.' Proceedings of the Prehistoric Society 52: 215-245.

Roe, D. (1979) 'Comment on "The Clactonian: an independent entity or an integral part of the Acheulian”, by M.Y.Ohel.' Current Anthropology, 20: 718-719.

Roe, D. (1981) The Lower and Middle Palaeolithic Periods in Britain. London: Routledge and Kegan Paul.

Roebroeks, W. (1988) 'From flint scatters to early hominid behaviour: a study of Middle Palaeolithic riverside settlements at Mastrict-Belvedere.' Analecta Praehistorica Leidensae 21.

Roebroeks, W., Conrad, N.J. and van Kolfschoten, T. (1992) 'Dense forests, cold steppes, and the Palaeolithic settlement of Northern Europe.' Current Anthropology 33:551586.

Rogers, A.R. (1988) 'Does biology constrain culture?' American Anthropologist 90: 818831.

Rolland, N. and Dibble, H.L. (1990) 'A new synthesis of Middle Palaeolithic variability.' American Antiquity 55:480-499.

Rozin, P. (1976) 'The evolution of intelligence and access to the cognitive unconscious.' In J.N.Sprague and A.N.Epstein (eds) Progress in Psychobiology and Physiological Psychology. New York: Academic Press.

Rozin, P. and Schull, J. (1988) 'The adaptive-evolutionary point of view in experimental psychology.' In R.C.Atkinson, R.J.Herrnstein, G.Lindzey and R.D.Luce (eds) Stevens' Handbook of Experimental Psychology, Vol. 1: Perception and Motivation, pp. 503-546. New York: John Wiley and Sons.

Sackett, J. (1982) 'Approaches to style in lithic archaeology.' Journal of Anthropological Archaeology 1:59-112.

Shackleton, NJ. and Opdyke, N.D. (1973) 'Oxygen isotope and palaeomagnetic stratigraphy of equatorial Pacific core, V28-238.' Quaternary Research 3: 39-55.

Straus, L.G. (1990) 'The original arms race: Iberian perspectives on the Solutrean phenomenon.' In J.Kozlowski (ed.) Feuilles du Pierre: Les Industries a Pointes Foliacées du Paléolithique Supérieur Européen, pp. 425-447, ERAUL 42. Liège: Université de Liège.

Stringer, C. and Gamble, C. (1993) In Search of the Neanderthals. London: Thames and Hudson.

Stuart, A.J. (1982) Pleistocene Vertebrates in the British Isles. New York: Longman. 
Susman, R.L. (1991) 'Who made Oldowan tools? Fossil evidence for tool behaviour in Plio-Pleistocene hominids.' Journal of Anthropological Research 47: 129-151.

Svoboda, J. (1987) 'Lithic industries of the Arago, Vértesszöllös, and Bilzingsleben hominids: comparisons and evolutionary interpretation.' Current Anthropology 28:219-227.

Tomasello, M. (1990) 'Cultural transmission in tool use and communicatory signalling of chimpanzees.' In S.Parker and K.Gibson (eds) Language and Intelligence in Monkeys and Apes: Developmental Perspectives, pp. 274-311. Cambridge: Cambridge University Press.

Tomasello, M., Davis-Dasilva, M., Camak, L. and Bard, K. (1987) 'Observational learning of tool use by young chimpanzees.' Human Evolution 2:175-183.

Tomasello, M., Kruger, A.C. and Ratner, H.H. (1993) 'Cultural learning.' Behavioural and Brain Sciences 16:495-552.

Tooby, J. and Cosmides, L. (1989) 'Evolutionary psychology and the generation of culture, part I.’ Ethology and Sociobiology 10:29-49.

Torrence, R. (1983) 'Time budgeting and hunter-gatherer technology.' In G. Bailey (ed.) Hunter-Gatherer Economy in Prehistory: A European Perspective, pp. 11-22. Cambridge: Cambridge University Press.

Toth, N. (1985) 'The Oldowan reassessed: a close look at early stone artefacts.' Journal of Archaeological Science 12:101-120.

Toth, N. and Schick, K. (1993) 'Early stone industries and inferences regarding language and cognition.’ In K.Gibson and T.Ingold (eds) Tools, Language and Cognition in Human Evolution, pp. 346-362. Cambridge: Cambridge University Press.

Toth, N., Schick, K., Savage-Rumbaugh, S., Sevcik, R.A. and Rumbaugh, D.M. (1993) 'Pan the tool-maker: Investigations into the stone tool-making and tool-using capabilities of a Bonobo (Pan paniscus)' Journal of Archaeological Science 20:81-91.

Turner, C. (1970) 'The Middle Pleistocene deposits at Marks Tey, Essex.' Philosophical Transactions of the Royal Society, B 257:373-440.

Tyldesley, J. (1986) The Wolvercote Channel Handaxe Assemblage: A Comparative Study. Oxford: British Archaeological Reports, British Series 152.

van Schaik, C.P. (1983) 'Why are diurnal primates living in groups?' Behaviour 87:120144.

Vértes, L. (1975) 'The Lower Palaeolithic site of Vértesszöllös, Hungary.' In R. BruceMitford (ed.) Recent Archaeological Excavations in Europe, pp. 287-301. London: Routledge and Kegan Paul.

Villa, P. (1991) 'Middle Pleistocene prehistory in southwestern Europe: the state of our knowledge and ignorance.' Journal of Anthropological Research 47:193-217.

Visalberghi, E. and Fragaszy, D. (1990) 'Do monkeys ape?' In S.Parker and K. Gibson (eds) Language and Intelligence in Monkeys and Apes: Developmental Perspectives, pp. 247-73. Cambridge: Cambridge University Press.

West, R.G. (1977) Pleistocene Geology and Biology. New York: Longman.

Whiten, A. (1989) 'Transmission mechanisms in primate cultural evolution.' Trends in Ecology and Evolution 4:61-62.

Whiten, A. (ed.) (1991) Natural Theories of Mind: Evolution, Simulation and Development of Everyday Mindreading. Oxford: Basil Blackwell.

Whitten, P. (1987) 'Infants and adult males.' In B.B.Smuts, D.L.Cheney, R.M. Seyfarth, R.W.Wrangham and T.T.Struhsaker (eds) Primate Societies, pp. 343-357. Chicago: University of Chicago Press.

Wiessner, P. (1983) 'Style and social information in Kalahari San projectile points.' 
American Anthropologist 48:253-276.

Wrangham, R. (1987) 'Evolution of social structure.' In B.B.Smuts, D.L. Cheney, R.M.Seyfarth, R.W.Wrangham and T.T.Struhsaker (eds) Primate Societies, pp. 283296. Chicago: University of Chicago Press.

Wymer, J. (1974) 'Clactonian and Acheulian industries in Britain: their character and significance.' Proceedings of the Geological Association 85:391-421.

Wymer, J. (1979) 'Comment on "The Clactonian: an independent entity or an integral part of the Acheulian,” by M.Y.Ohel.' Current Anthropology 20:719.

Wymer, J. (1985) Palaeolithic Sites of East Anglia. Norwich: GeoBooks.

Wymer, J. (1988) 'Palaeolithic archaeology and the British Quaternary sequence.' Quaternary Science Reviews 7:79-98.

Wynn, T. (1989) The Evolution of Spatial Competence. Urbana: University of Illinois Press.

Wynn, T. and McGrew, W. (1988) 'An ape's eye view of the Oldowan.' Man (n.s.) 24:383-398.

Wynn, T. and Tierson, F. (1990) 'Regional comparison of the shapes of later Acheulian handaxes.' American Anthropologist 92:73-84. 